\title{
Immune Reconstitution Approaches for
} HIV

National Cancer Institute

\section{Source}

National Cancer Institute. Immune Reconstitution Approaches for HIV. NCI Thesaurus.

Code C18844.

Develop and evaluate strategies that will enhance, restore, and/or maintain the immune systems of HIV-infected individuals and extend our understanding of immunopathogenesis. 